\title{
Solubility Measurement and Correlation for Amrinone in Four Binary Solvent Systems at (278.15 - 323.15)
}

\section{$\mathrm{K}$}

Songling $\mathrm{Wu}$, Yuli Shi*, Haojian Zhang

School of Materials and Chemical Engineering, Ningbo University of Technology, Fenghua Road 201, Ningbo

315016, Zhejiang, People's Republic of China

Corresponding author. Phone: +86 574 88918259; Fax: +86 57488918259 .

E-mail address: yuli_shi@tju.edu.cn 


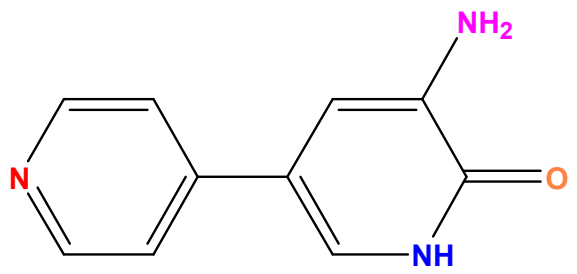

Fig. S1. Chemical structure of amrinone. 


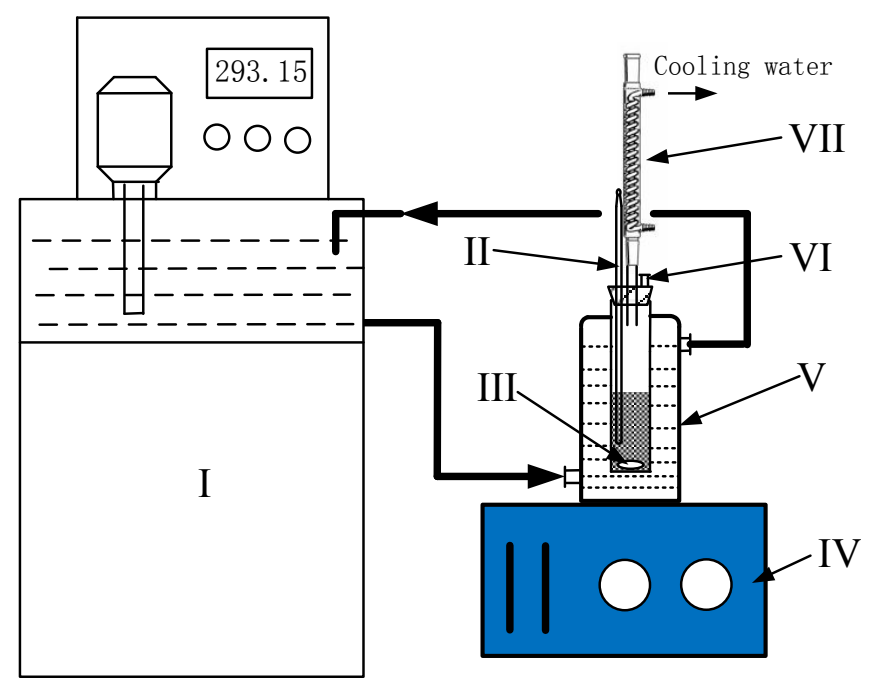

Fig. S2. Schematic diagram of experimental apparatus: I, smart thermostatic water bath; II, mercury-in-glass thermometer; III, magnetic stirrer; IV, stirrer controller; V, jacketed glass vessel; VI, sampling port; VII, condenser. 


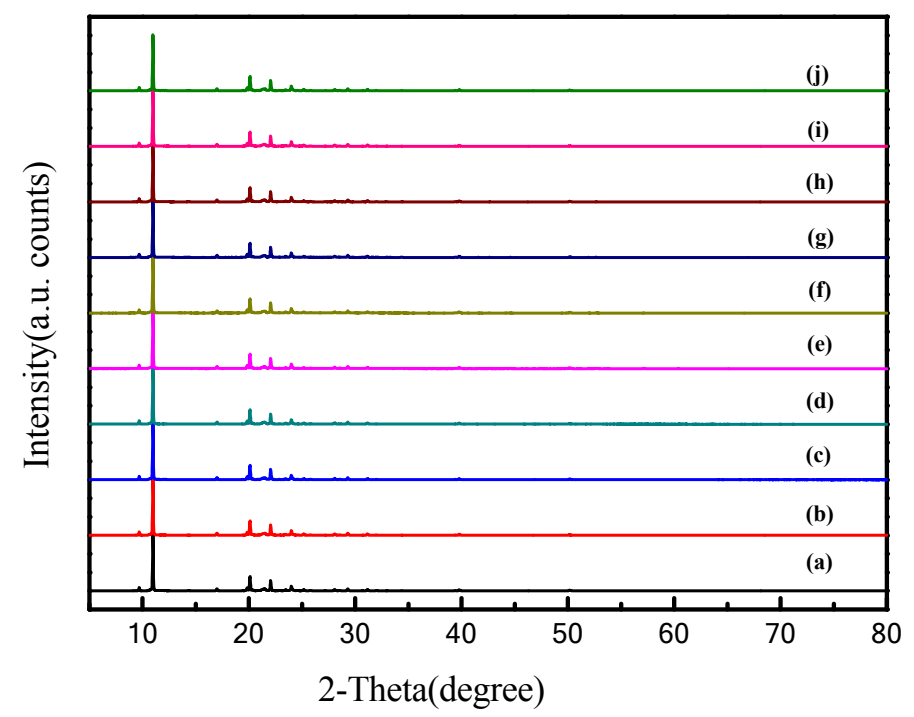

Fig. S3. XPRD patterns of amrinone: (a) raw material; (b) crystallized in methanol; (c) crystallized in ethanol; (d) crystallized in EG; (e) crystallized in DMF; (f) crystallized in water; (g) crystallized in methanol + water mixture; (h) crystallized in ethanol + water mixture; (i) crystallized in EG + water mixture; (j) crystallized in DMF + water mixture. 